\title{
Announcing the launching of Integrative Pharmacology, Toxicology, and Genotoxicology
}

\author{
Marcelo L. Larramendy ${ }^{1 *}$ and Ofelia A. Olivero ${ }^{2}$ \\ ${ }^{1}$ Faculty of Natural Sciences and Museum, National University of La Plata, La Plata, Argentina, Argentina \\ ${ }^{2}$ Senior Reseacher, National Cancer Institute, NIH, USA
}

We would like to welcome our readers to Integrative Pharmacology, Toxicology, and Genotoxicology, a new journal for the twenty-first century. The new journal is completely Open Access and online-only, and covers a broad range of topics in the fields of Pharmacology, Toxicology, and Genotoxicology basic and clinical related sciences. Integrative Pharmacology, Toxicology, and Genotoxicology is published by OA Text, a new academic open-access scientific publisher, which showcases research and ideas aimed to inform human health by linking basic research and clinical practice to be benefit of the society worldwide. In agreement, OA Text's Journals are led by prominent researchers, each embracing the concept that basic knowledge can foster sustainable clues and solutions for society and committed to the proposition that the goals of scientific inquiry are definitively aligned with the principles of open knowledge for the population health on a global basis. So far, OA Text Publisher possess a large portfolio of different Journals covering a wide spectrum of scientific research including Molecular Medicine, Cancer Science and Therapeutics, Obesity and Diabetes, Food, Nutrition and Metabolism, Dermatology, Cardiology, Dental, Oral and Craniofacial Research, Clinical Research and Trials, among others.

Integrative Pharmacology, Toxicology and Genotoxicology (IPTG) is an international peer-reviewed journal that publishes original and high-quality research papers in multiple areas of the pharmaceutical, toxicology, and genotoxicology sciences. This includes basic and clinical pharmacology and molecular (genetic), biochemical and cellular pharmacology, toxicology, geno-and cytotoxicity and related fields. It also covers clinical pharmacology: pharmacokinetics, pharmacodynamics, therapeutic drug monitoring, drug/drug interactions, pharmacogenetics/genomics, pharmacoepidemiology, pharmacovigilance, pharmacoeconomics, randomized controlled clinical trials and rational pharmacotherapy, biochemical pharmacology, molecular pharmacology, immunopharmacology, drug legislation and safety, environmental pharmacology, analytical toxicology, and neuropsychopharmacology.

The Journal also publishes the research involving both basic and translational aspects of genotoxicology: the interactions between DNA and various "genotoxic" agents (ionizing radiation, solar radiation, chemical carcinogens, and emerging pollutants, among others) as well as the resulting DNA damage using biomarkers fortoxicity, cytotoxicity, and genotoxicity in different biotic matrices.

The journal welcomes submissions mainly original research papers, short communications, invited reviews, case studies and editorial commentary and news, opinions \& perspectives and book reviews written at the invitation of the editor from all fields of experimental and clinical pharmacology and toxicology, including clinical research and trials. We offer an efficient, fair and friendly peer review service, and are committed to publishing all sound science, provided that there is some advance in knowledge presented by the work.

Scientific rigor and quality will be our guiding principles. We also invite letters to the editor that comment on publications or other relevant issues in the broad field of pharmacology and toxicology. We have assembled an editorial board with a large variety of interests in the field. Although we are a new journal, we offer many advantages for authors, including rapid publication, wide dissemination of your Open Access paper, and the full resources of OA Text scientific publishing group. We look forward to your submissions.
Copyright: (C2015 Larramendy ML. This is an open-access article distributed under the terms of the Creative Commons Attribution License, which permits unrestricted use, distribution, and reproduction in any medium, provided the original author and source are credited.
Correspondence to: Marcelo L. Larramendy, Ph.D. Faculty of Natural Sciences and Museum, National University of La Plata, La Plata, Argentina, Argentina, E-mail: marcelo.larramendy@gmail.com

Ofelia A. Olivero, Senior Reseacher, National Cancer Institute, NIH, USA, E-mail: oliveroo@gmail.com

Received: January 16, 2015; Accepted: January 16, 2015; Published: January 22, 2015 